\title{
Effect of Hydroalcoholic Extract of Prosopis farcta Pod on Liver Histopathology and Malondialdehyde Level in Streptozotocin Diabetic Rats
}

\author{
Hajinezhad M.R.* PhD, Esmaeel Zadeh Bahabadi S. ${ }^{1}$ PhD, Miri H.R. ${ }^{2}$ PhD, Davari S.A. ${ }^{3}$ PhD, Darvish \\ Sargazi M. 1
}

*Basic Sciences Department, Veterinary Medicine Faculty, University of Zabol, Zabol, Iran
1Biology Department, Basic Sciences Faculty, University of Zabol, Zabol, Iran
2Basic Sciences Department, Medicine Faculty, Torbat Heydarieh University of Medical Sciences, Torbat
Heydarieh, Iran
3Pathobiology Department, Veterinary Medicine Faculty, University of Zabol, Zabol, Iran

\begin{abstract}
Aims: Diabetes is a common endocrine disorder that can lead to hyperglycemia and hyperlipidemia. The aim of this study was to investigate the effect of hydroalcoholic extract of pod Prosopis fracta, on liver histopathology and tissue level of malondialdehyde (MDA) in streptozotocin-induced diabetic rats.

Materials \& Methods: 45 male Wistar rats (200-300g) were divided into 3 groups; control, diabetic and Prosopis farcta extract treated diabetic. Type 1 diabetes was induced in by injection of streptozotocin $(42 \mathrm{mg} / \mathrm{kg})$. One week after diabetes induction, Prosopis farcta extract $(300 \mathrm{mg} / \mathrm{kg}$ of body weight) was administered to treated diabetic group by gavage for 30 days. Hepatic histological changes were assessed with Hematoxylin-Eosin staining under light microscopy. The liver concentration of MDA was determined as thiobarbituric acid reactive substances (TBARS). The obtained data were statistically analyzed using Students $\mathrm{T}$ and Mann-Whitney rank sum tests.

Findings: Administration of Prosopis fracta extract decreased the concentration of malondialdehyde in liver tissue of treated diabetic group in comparison to diabetic group significantly $(\mathrm{p}<0.05)$. Inflation and vacuolation of hepatocytes were observed with disarrangement of hepatic cords and sinusoidal narrowing. All previous signs were improved in Prosopis fracta treated group.

Conclusion: Hydro-alcoholic extract of Prosopis fracta pod can reduce the level of malondialdehyde as a marker of lipid peroxidation in liver and prevent the histopathological changes of liver associated with diabetes.
\end{abstract}

\section{Keywords}

Prosopis [http://www.ncbi.nlm.nih.gov/mesh/68029862];

Pathology [http://www.ncbi.nlm.nih.gov/mesh/68010336];

Liver [http://www.ncbi.nlm.nih.gov/mesh/68008099];

Diabetes Mellitus [http://www.ncbi.nlm.nih.gov/mesh/68003920]

\footnotetext{
${ }^{*}$ Corresponding Author

Tel: +9854322326567

Fax: +9854322240735

Address: Veterinary Medicine Faculty, University of Zabol, Kilometer $2^{\text {nd }}$ of Bonjar-Pardis Road, Zabol, Iran. Postal Code: 98613-35856

hajinezhad@uoz.ac.ir

Received: November 12, $2014 \quad$ Accepted: February 23, 2015 ePublished: April 16, 2015
} 
تأثير عصاره هيدروالكلى غلاف ميوه كهور مهى بر بران

بيمارى ديابت يكى از مسايل يبحيجيده در علم يزشكى است. اين

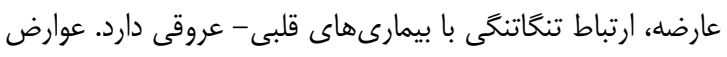

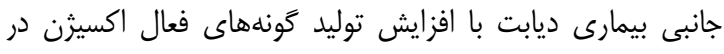

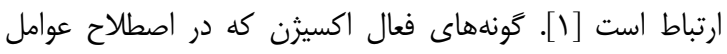

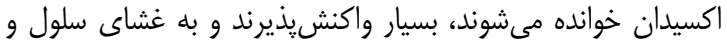

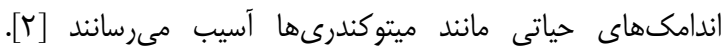

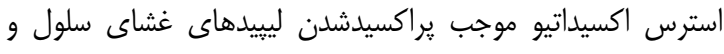

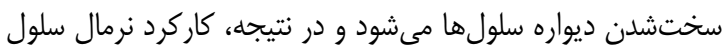

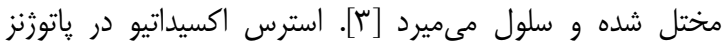

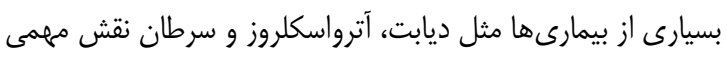

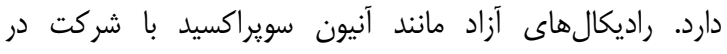

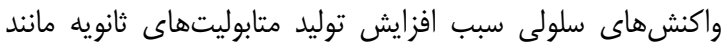

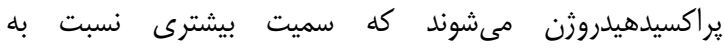

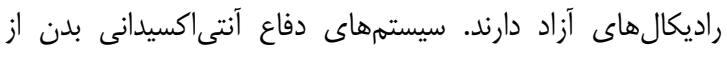

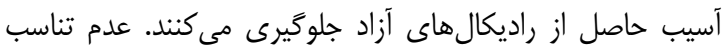

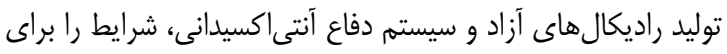

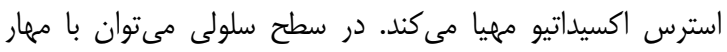

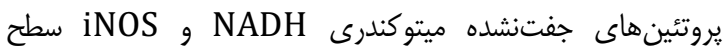
استرس اكسيداتيو را كاهش داد [ث].

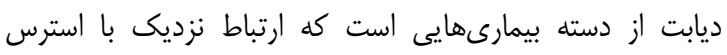

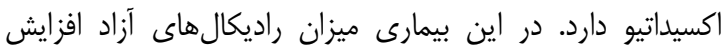

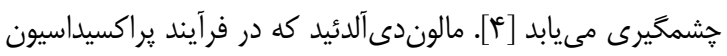

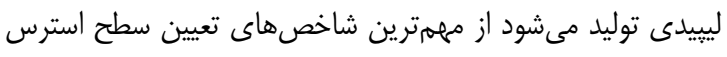

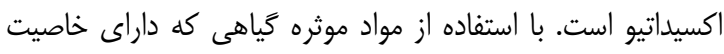

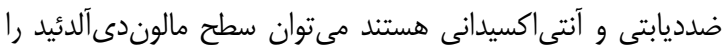

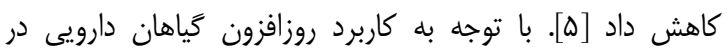

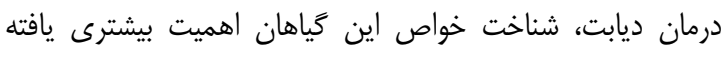

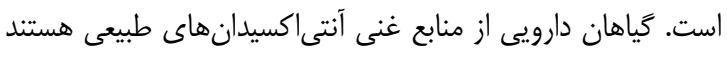

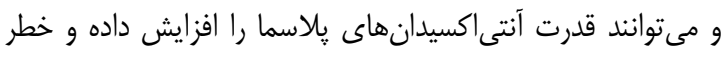

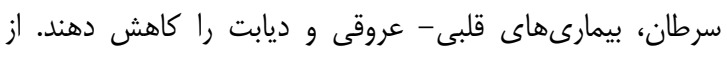

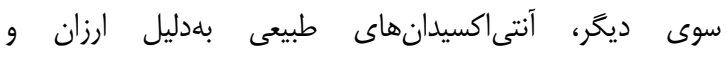

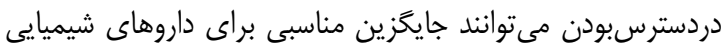

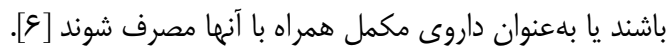

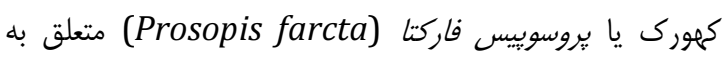

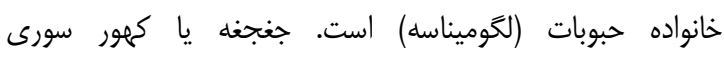

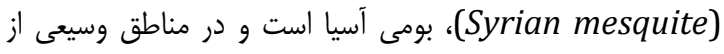

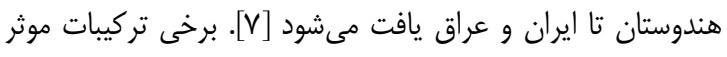

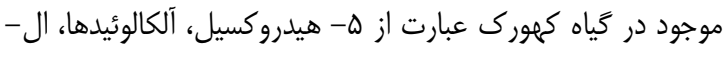

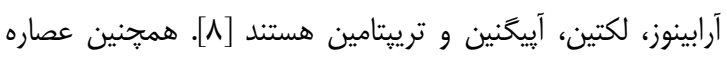

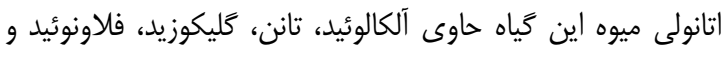

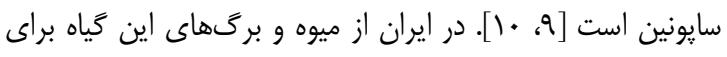
هيستوياتولوزى و ميزان مالون دى آلدئيد كبد در هرو

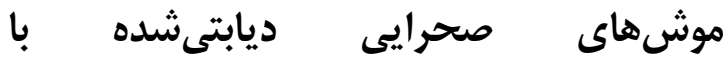
استر يتوزوتوسين

PhD محمدرضا حاجىنزاد كروه علوم پايه، دانشكده داميزشكى، دانشخاه زابل، زابل، ايران

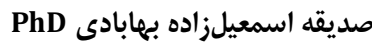

كروه زيستشناسى، دانشكده علوم پايه، دانشگاه زابل، زابل، ايران

حميدرضا ميرى PhD

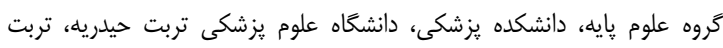
حيدريه، ايران

سيدهآيدا داورى آيران

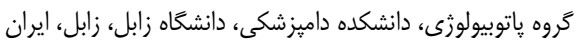

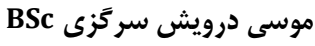
كروه زيستشناسى، دانشكده علوم يايه، دانشكاه زابل، زابل، ايران

جكيده

اهداف: ديابت اختلال آندوكرينى شايعى است كه باعث هييرلييبدمى و

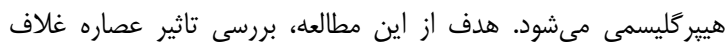

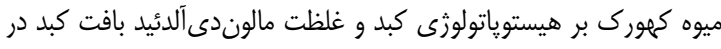

موشهاى صحرايى ديابتى بود.

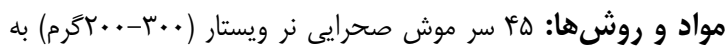

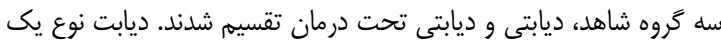
با تزريق داخلصفاقى استريتوزوتوسين (بأميلى گرم بر كيلوگرم) القا شد.

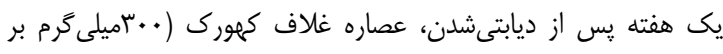

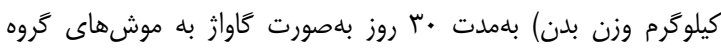

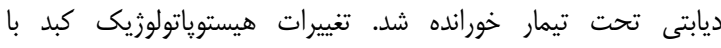

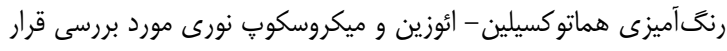

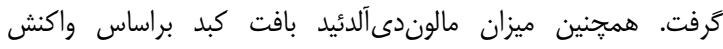

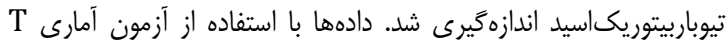
استيودنت و آزمون مجموع رتبهاى من - ويتنى بررسى شدند.

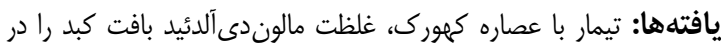

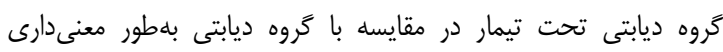

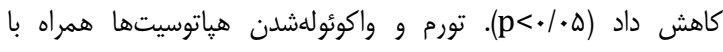

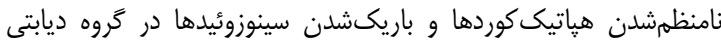

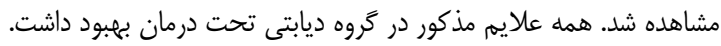

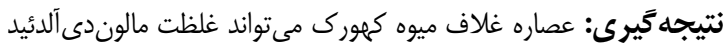

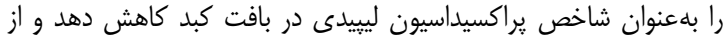
آسيب كبدى ناشى از ديابت جلوگيرى كند. كليدوازهها: كهورى، آسيبشناسى، كبد، ديابت شئ شيرى كنين

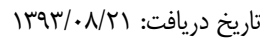

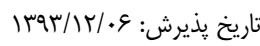
"نويسنده مسئول: hajinezhad@uoz.ac.ir 


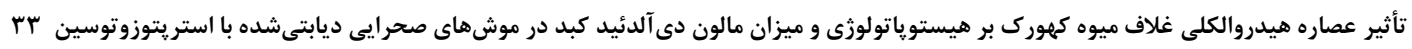

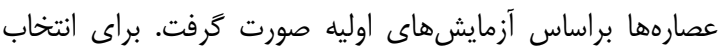
دوز ابتدا با بررسى منابع مختلف، غلظتى از عصاره كه محققان دماسيخر نيز در عصارههاى گياهان ديگر به نتيجه رسيده بودند انتخاب شهد

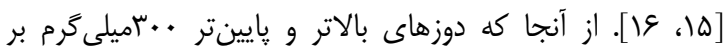

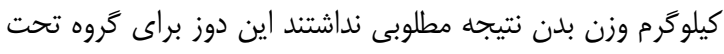

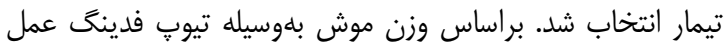

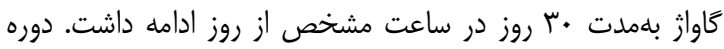

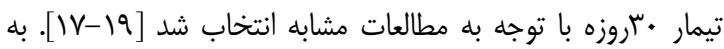
موشهاى گروه شاهد در اين مدت سرم فيزيولوزى خورانده شد تا

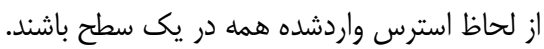
عصارهَيرى از كَياه كهورى: بلمنظور تهيه عصاره، گياه كهورى از اداره منابع طبيعى زابل تهيه شد و سيس به ئروهشكده

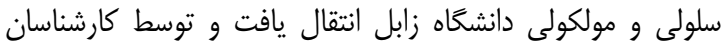
كياهشناسى شناسايى و تاييد شد. ميوه جمعآورى مشده در در سايه

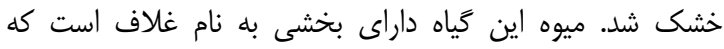

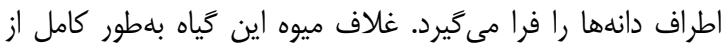
دانهها جدا و آسياب شد. يس از آسيابكردن، در . .."اكرم بر ليتر

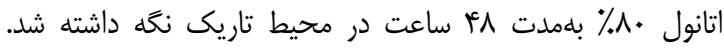

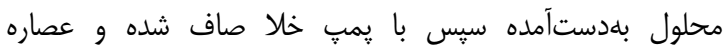

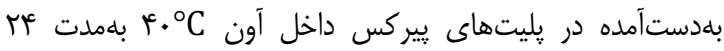

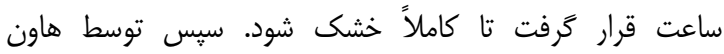

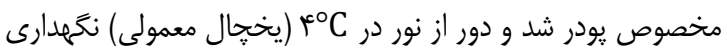

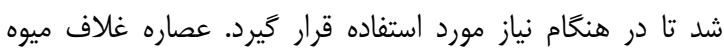
كهورى بلمدت ·r روز به موشهاى صحرايى بلهصورت كاواز

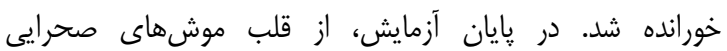

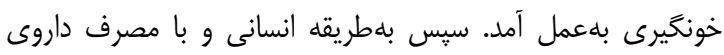

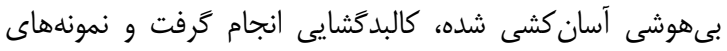

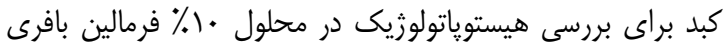

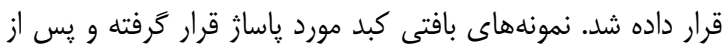
تهييه مقاطع أ تا هميكرونى بلهوسيله هماتوكسيلين و ائوزين

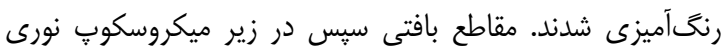

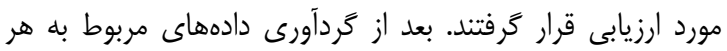

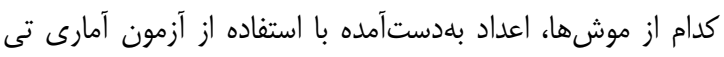

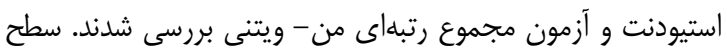

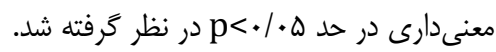

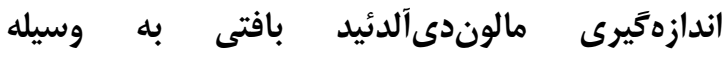

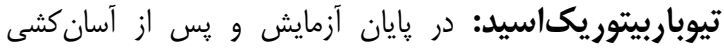

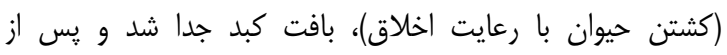

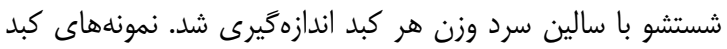

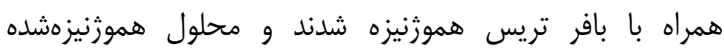
سانتريفوز شد. براى جلوگيرى از تخريب يروتئينها و آنزيهها، تمام

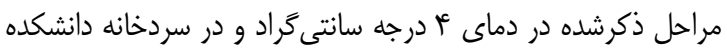

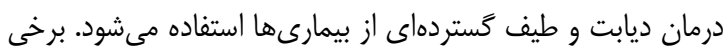

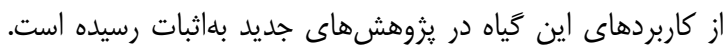

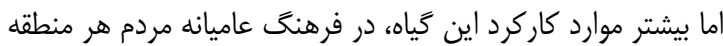
ريشه دارد و توسط مراجع دانشگاهى و علمى بررسى نشده است؛

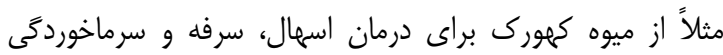

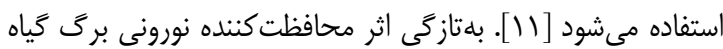
كهورى بهاثبات رسيده است [ [I]]. برى اين گياه براى درمان زخهم ناشى از ديابت كاربرد دارد. اما تاكنون مكانيزم دقيق تاثير آن بلهدرستى درك نشده است [111]. در كشور اردن نيز از عصاره حاصل

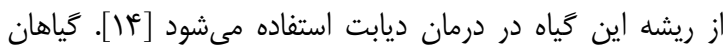

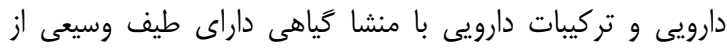

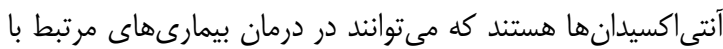
ديابت موثر باشند. عوارض جانبى كمتر و قيمت مناسب تركيبات

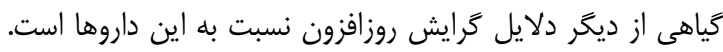

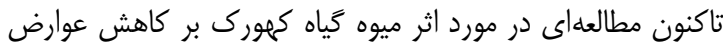
جانبى ناشى از بيمارى ديابت انجام نشده است. هدف از اين مطالعه، بررسى اثر عصاره غلاف گياه كهورى بر بر برك

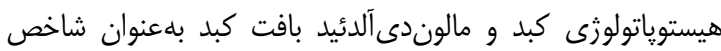
استرس اكسيداتيو بود.

\section{مواد و روشها}

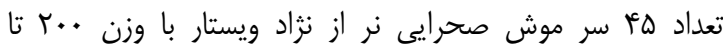

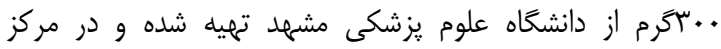
يرورش دانشكده داميزشكى دانشگاه زابل نكخهدارى شدند. حيوانات

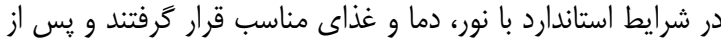

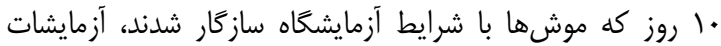
انجام گرفت. اين يزوهش براساس قوانين بينالمللى در مورد

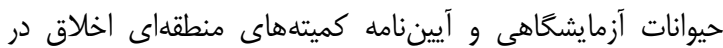
يثوهش هاى علوم يزشكى به انجام رسيد.

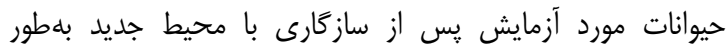
تصادفى به گروههاى هاتايى شاهد، ديابتى و ديابتى تحت درمان با باني

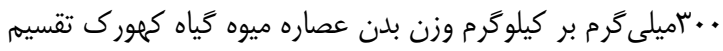
شدند. موشهاى صحر ايى گروه دوم و سوم با تزريق داخلصفاقى

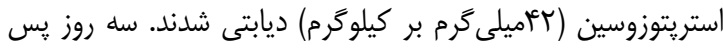
از تزريق، ديابتىشدن موشها با اندازهگيرى قند خون تاييد شد.

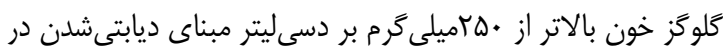

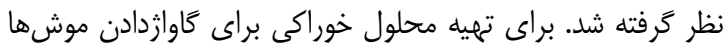

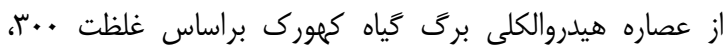

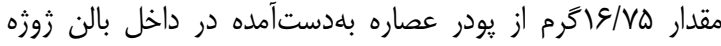

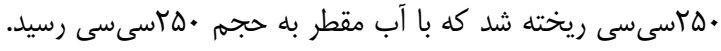
داخل بالن زوزه مخَنت انداخته و روى هيتر قرار داده شد تا خوب

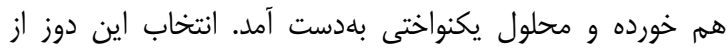


قرار كرفتهاند، بهعلت كمبود فضا نسبت به حالت طبيعى باريكتر

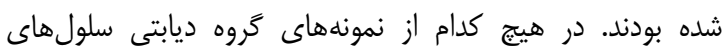

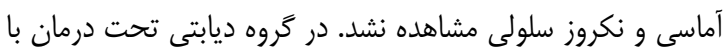

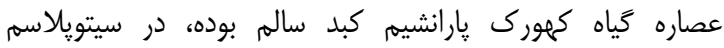

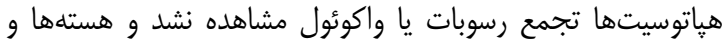
سينوزوئيدها نيز وضعيت طبيعى داشتند (شكل () ).
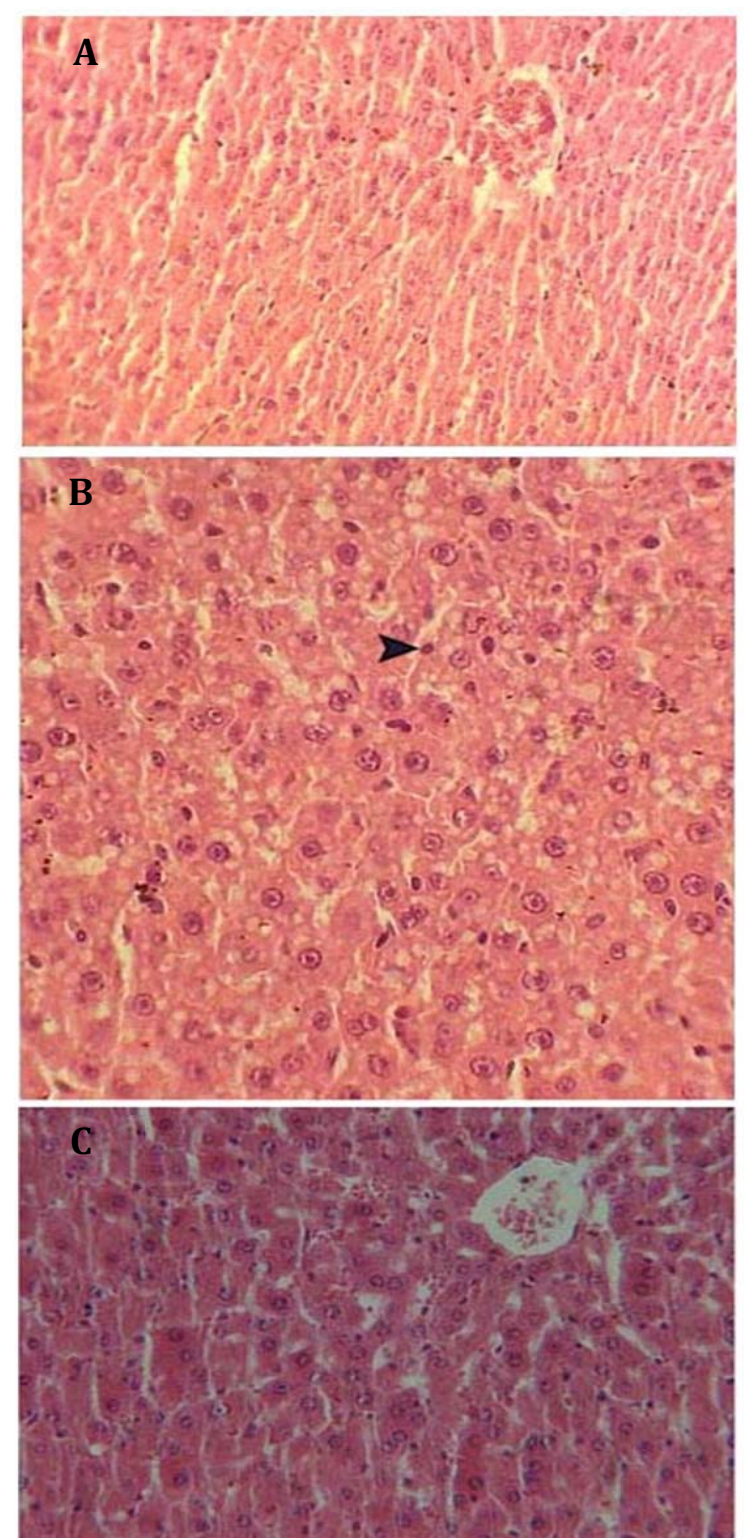

شكل () (A يارانشيم كبد موش صحرايى در تروه ديابتى. تجمع رسوبات

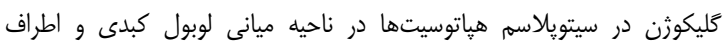

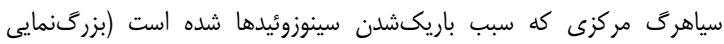

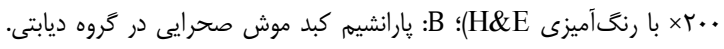

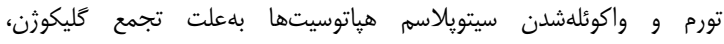

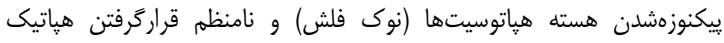

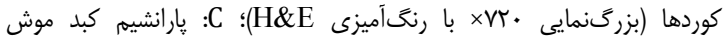

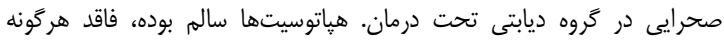

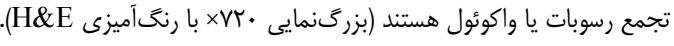

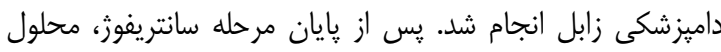

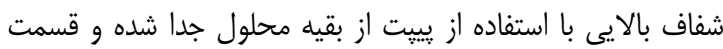

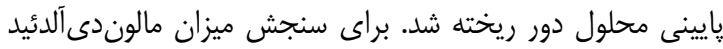

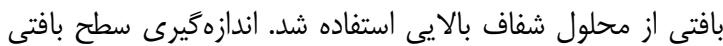

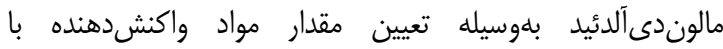
تيوباربيتوريكاسيد و دستورالعمل كيت (انزان شيمى، تهران) انجام شد. براساس دستورالعمل كيت، ..اميكروليتر از بافت هموزنيزه،

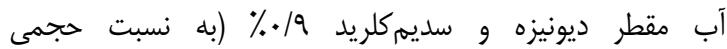

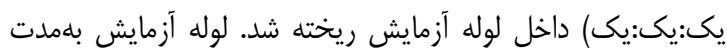

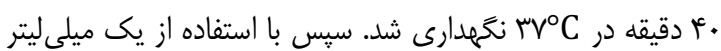

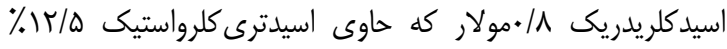

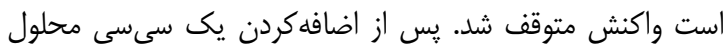

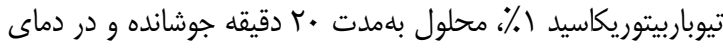

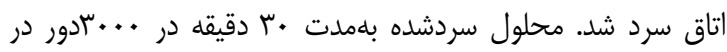
دقيقه سانتريفوز شد. جذب نورى محلول در طول موج كسمانانومترد

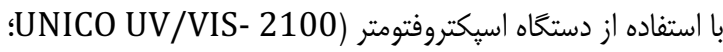
ايالات متحده) سنجش شد. تجزيه وتحليل آمارى دادهها: از نظر آمارى تمام نتايج

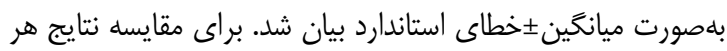

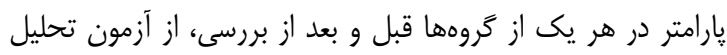

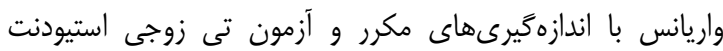

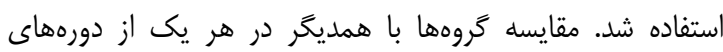

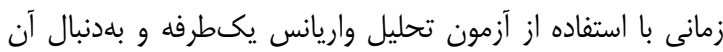

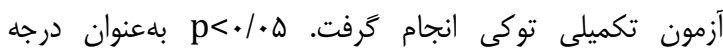

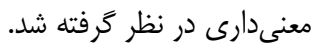

يافتهها

غلظت مالوندى آلدئيد بافتى تفاوت معنىدارى بين دو كروه شاهد

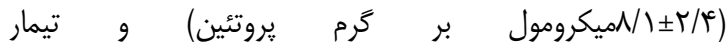

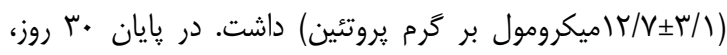

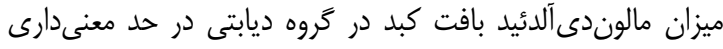

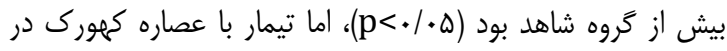

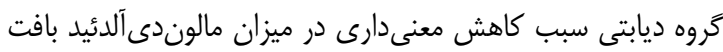

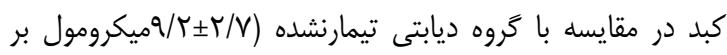
كرم يروتئين) شد.

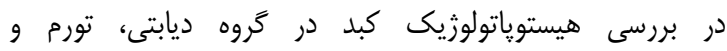

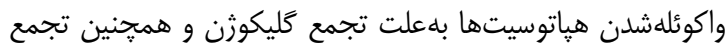

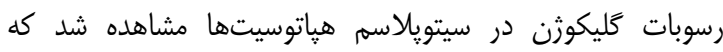
قسمت عمده اين ضايعات در ناحيه مركز لوبولى و واطراف

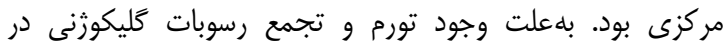
سيتويلاسه هياتوسيتها، هستهها بيكنوزه و هياتيك كوردها نون نامنظم

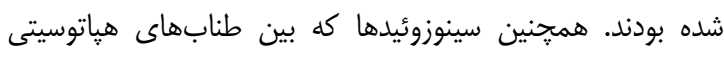

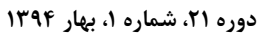
فصلنامه افق دانش 


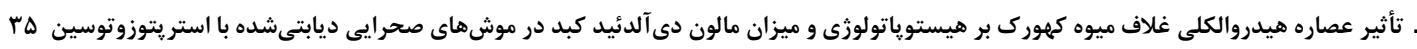

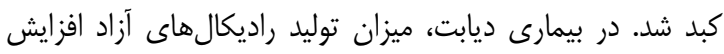

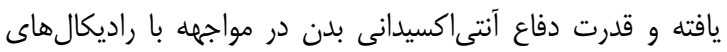

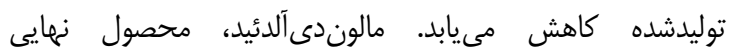

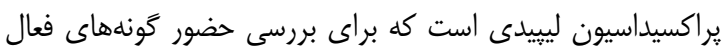

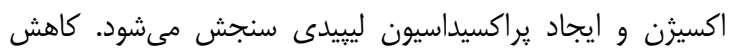

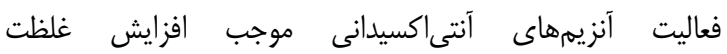

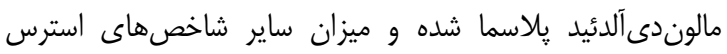

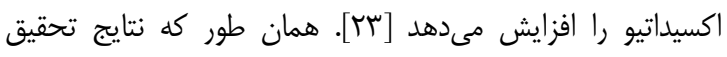

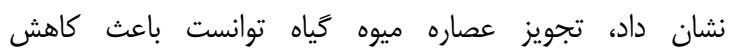
يراكسيداسيون ليييدى شود. عصاره برى اين زياه دارويى موجب افزايش حساسيت سلولها لها به

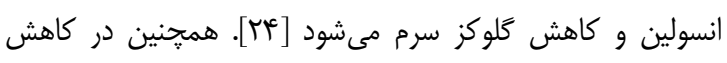

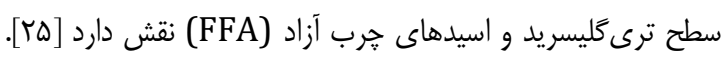

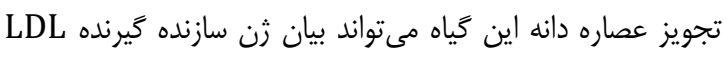

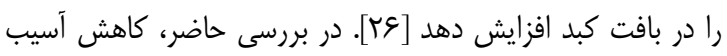
كبدى ناشى از هييرليييدمى مىتواند در نتيجه اين مكانيزمها باشد.

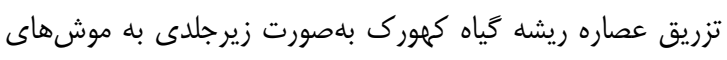

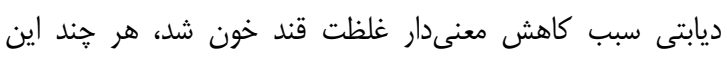

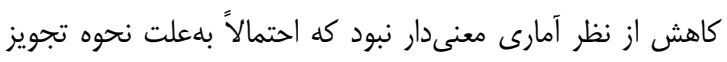

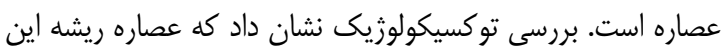
گياه فاقد اثرات سمى است [TV]. بررسى حاضر نشان دان داد تجويز

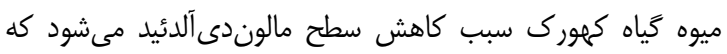

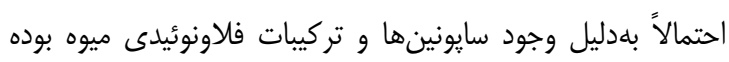
كه از آغاز واكنش زنجيرهاى راديكال آزاد جلوخيرى مى كى كنند.

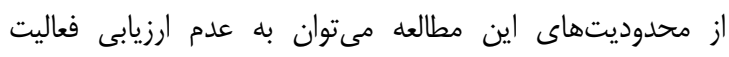
آنزيههاى آنتىاكسيدانى كبد مانند سويراكسيدديسموتاز، كاتالاز و و

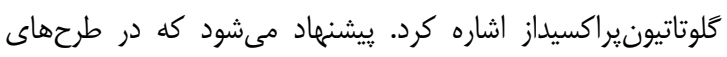
مشابه آتى، شاخصهاى مرتبط با استرس اكسيداتيو در بافتهاى ديخر مانند كليه، قلب و مغز بررسى شود. در يايان، با توجه به مانه يافتههاى مطالعه حاضر بلنظر مىرسد كه عصاره گياه كهورى سطح مالوندى آلدئيد بافت كبد را در موشهاف بهاى صحرايى ديابتى

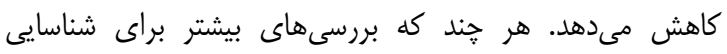

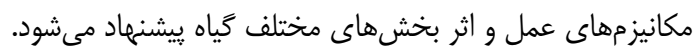

نتيجه كيرى

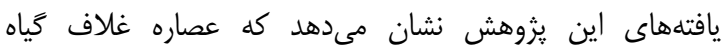

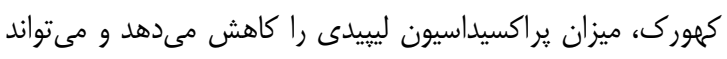
از عوارض ثانويه بيمارى ديابت جلوكيرى كند.

تشكر و قدردانى: از همكارى آقاى مهدى ميرشكار براى انجام

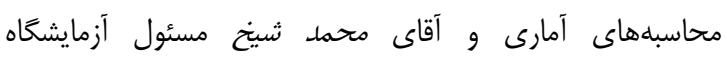
فيزيولوزى تشكر مى شود.

در يزوهش كنونى اثر عصاره ميوه كهورى بر غلظت مالوندى آلدئيد

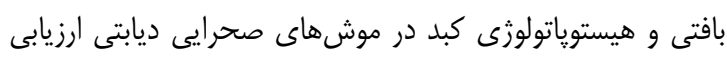

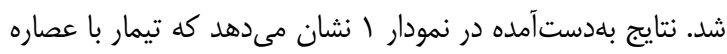

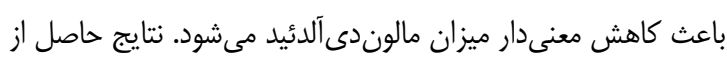

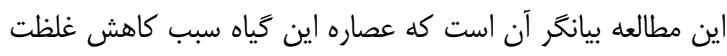

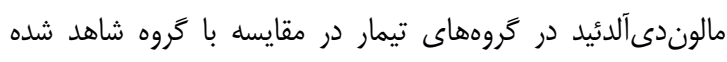

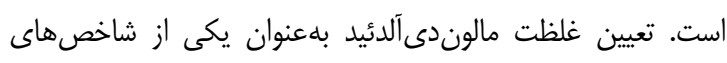

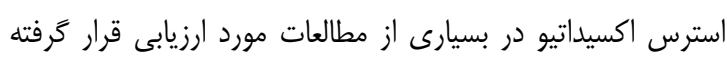

است [1N].

كياه كهورى داراى تركيباتى با خاصيت آنتىاكسيدان است كه

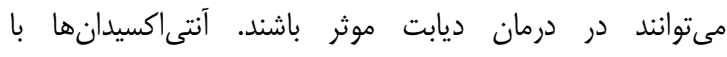

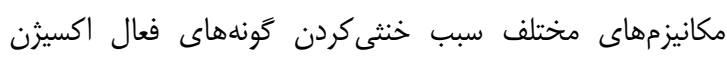

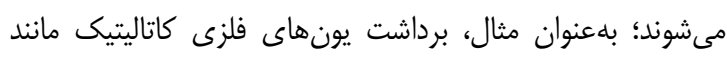

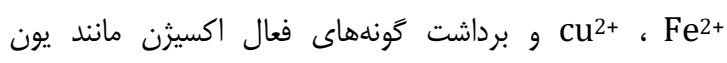

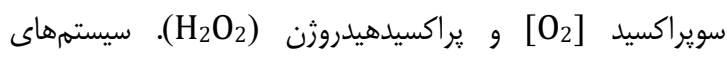

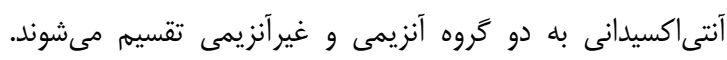

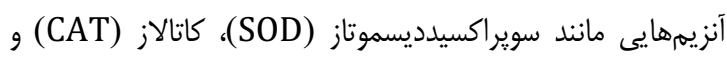

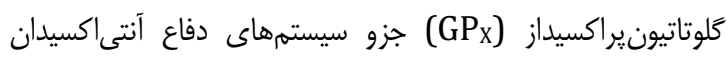

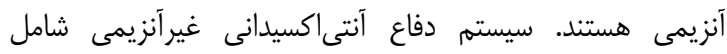
آنتى اكسيدانهايى مانند اسيدآسكوربيك، ويتامين E (آلفا توكوفرول)

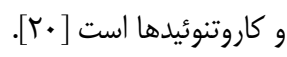
كياه كهورى سرشار از فلاونوئيدها و تركيبات فنوليك است كه إنهات

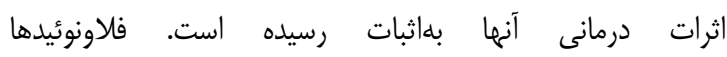

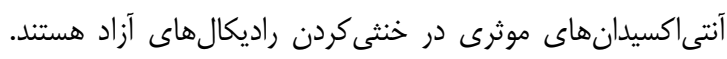

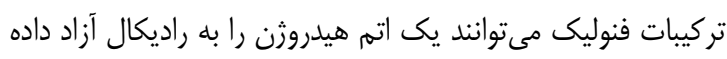

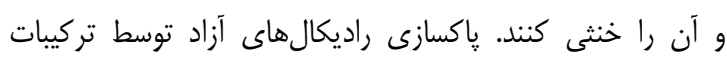

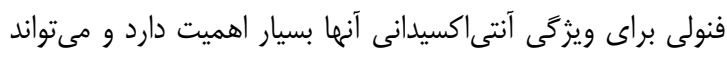

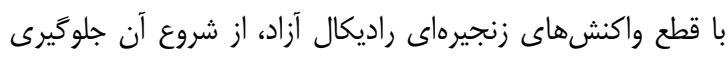

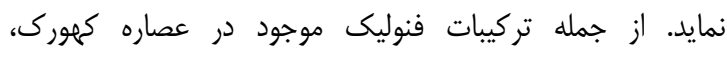

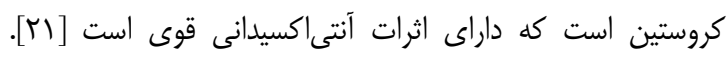

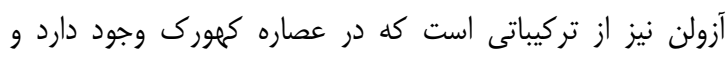

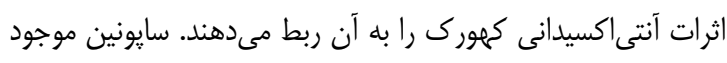

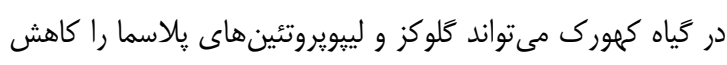

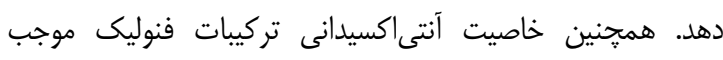

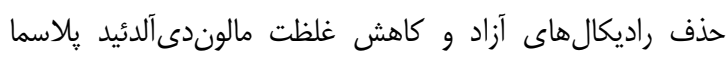

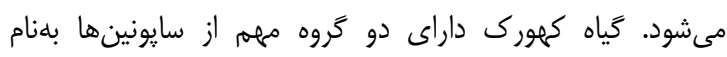

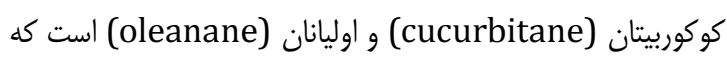

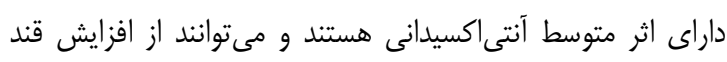

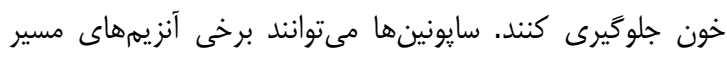

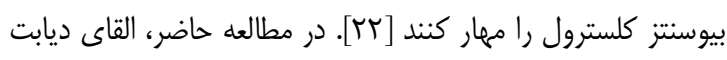
در موشهاى صحرايى سبب افزايش ميزان مالوندى آلدئيد بافت دئ دافي 
compression in Rats. J Gorgan Uni Med Sci. 2012;14(4):39-43. [Persian]

13- Ranjbar-Heidari A, Khaiatzadeh J, Mahdavi-Shahri N, Tehranipoor M. The effect of fruit pod powder and aquatic extract of prosopis farcta on healing cutaneous wounds in diabetic Rat. Zahedan J Res Med Sci. 2012;14(5):16-20.

14- Al-Aboudi A, Afifi FU. Plants used for the treatment of diabetes in Jordan: A review of scientific evidence. Pharm Biol. 2011;49(3): 221-39.

15- Hedayati M, Pouraboli I, Pouraboli B, Dabiri Sh, Javadi A. Effects of otostegia persica extract on serum level of glucose and morphology of pancreas in diabetic rats. Koomeh. 2012;13(2):201-8. [Persian]

16- Zare T, Mokhtari M, Mohammadi J.The effect of Hydroalcoholic extracts of prangos ferulacea on blood factors of kidney and liver functions in diabetic male wistar rats. J Fasa Univ of Med Sci. 2012;2(3):174-80. [Persian]

17- Rahbarian R, Sadooghi SD. Investigating the effects of aqueous extract of asafoetida resin on the serum level of insulin and blood glucose in type 1 diabetic rats. J Shahrekord Univ Med Sci. 2014;16(3):16-21. [Persian]

18- Nielsen F, Mikkelsen BB, Nielsen JB, Andersen HR, Grandjean P. Plasma malondialdehyde as biomarker for oxidative stress: Reference interval and effects of lifestyle factors. Clin Chem. 1997;43(7):1209-14.

19- Masjedi F, Gol A, Dabiri Sh, Javadi A. Preventive effect of garlic on histopathology of liver and markers of hepatic injury in streptozotocin-induced diabetic rats. Iran J Endocrinol Metabolism. 2009;11(4):433-41. [Persian]

20- Sies H. Strategies of antioxidant defense. Eur J Biochem. 1993;215(2):213-9.

21- Ali-Shtayeh MS, Jamous RM, Al-Shafie' JH, Elgharabah WA, Kherfan FA, Qarariah KH. Traditional knowledge of wild edible plants used in Palestine (Northern West Bank): A comparative study. J Ethnobiol Ethnomed. 2008;12(4):13.

22- Al-Jeboory AA, Alhusainy WAH. Cardiovascular studies on prosopis farcta. Fitoterapia. 1984;55:137-42. 23- Yaniv Z, Dafni A, Friedman B, Palevith D. Plants used for the treatment of diabetes in Israel. J Ethnopharmacol. 1987;19(2):145-51.

24- Afifi FU. Hypoglycemic effects of prosopis farcta. Int J Pharmacognosy. 1993;31(2):161-4.

25- Asadollahi K, Abassi N, Afshar N, Alipour M, Asadollafi p.. Investigation of the effects of prosopis farcta plant extract on rat's aorta. J Med Plants Res. 2010;4(2):142-7.

26- Asadollahi A, Sarir H, Omidi A, Torbati MB. Hepatoprotective potential of prosopis farcta beans extracts against acetaminophen-induced Hepatotoxicity in wister rats. Int J Prev Med. 2014;5(10):1281-5.

27- Jafari F, Minaiyan M, Hoseyni-Baharanchi M, HeidariBeni M. Anti-diabetic effect of prosopis farcta (Bank \& Soland) J. F. Macbar extract in rats. J Health Syst Res. 2013;Special Issue on Nutrition:1649-56. [Persian]

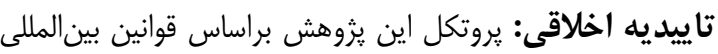

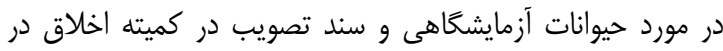

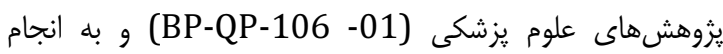

$$
\begin{aligned}
& \text { تعارض منافع: هيج گَونه تعارض منافع توسط نويسندگًان بيان } \\
& \text { نشده است. } \\
& \text { منابع مالى: مطالعه براساس پاياننامه كارشناسىارشد آقاى موسى }
\end{aligned}
$$

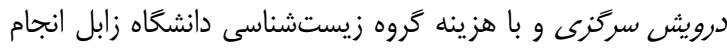

$$
\begin{aligned}
& \text { كرفت. } \\
& \text { منابع }
\end{aligned}
$$

1- Giacco F, Brownlee M. Oxidative stress and diabetic complications. Circ Res. 2010;107(9):1058-70.

2- Widlansky ME, Gutterman DD. Regulation of endothelial function by mitochondrial reactive oxygen species. Antioxid Redox Signal. 2011;15(6):1517-30.

3- Naudi A, Jove M, Ayala V, Cassanye A, Serrano J, Gonzalo $\mathrm{H}$, et al. Cellular dysfunction in diabetes as maladaptive response to mitochondrial oxidative stress. Exp Diabetes Res. 2012;2012:1-14

4- Victor VM, Rocha M, Herance R, Hernandez-Mijares A. Oxidative stress and mitochondrial dysfunction in type 2 diabetes. Curr Pharm Des. 2011;17(36):3947-58.

5- Esrefoglu M. Oxidative stress and benefits of antioxidant agents in acute and chronic hepatitis. Hepat Mon. 2012;12(3):160-7.

6- Ryan EA, Pick ME, Marceau C. Use of alternative medicines in diabetes mellitus. Diabet Med. 2001; 18(3):242-5.

7- Harzallah-Skhiri F, Ben Jannet H. Flavonoids diversification in organs of two prosopis farcta (Banks \& Sol.) Eig. (Leguminosea, Mimosoideae) populations occurring in the northeast and the southeast of Tunisia. J Appl Sci Res. 2005;1(2):130-6.

8- Marles RJ, Farnsworth NR. Antidiabetic plants and their active constituents. Phytomedicine. 1996;2(2):13789.

9- Ansari nik H, Saberi M, Jahantigh M, Ebrahimzadeh A. The evaluation of chemical composition and dry matter degradability of prosopis farcta fruit using in situ nylon bag technique. Int J Agric Crop Sci. 2013;5(9)972-5.

10- Molan AL, Mahdy AS. Iraqi medicinal plants: Total flavonoid contents, free-radical scavenging and bacterial beta-glucuronidase inhibition activities. IOSR J Dental and Med Sci. 2014;13(5)72-7.

11- Duthie G, Crozier A. Plant-derived phenolic antioxidants. Curr Opin Clin Nutr Metab Care. 2000; 3(6):447-51.

12- Tehranipour M, Mollashahi M, Javadmoosavi BZ. Effect of ethanolic extract of pod Prosopis farcta plant on neuronal density of anterior horn following Sciatic nerve 